\title{
Bactericidal Effect of Corona Discharges in Atmospheric Air
}

\author{
Igor V. Timoshkin, Member, IEEE, Michelle Maclean, Mark P. Wilson, Member, IEEE, \\ Martin J. Given, Senior Member, IEEE, Scott J. MacGregor, Member, IEEE, Tao Wang, and John G. Anderson
}

\begin{abstract}
This paper explores the possibilities of using impulsive and steady-state corona discharges for biodecontamination operations. A high tension tubular corona electrode was stressed with positive or negative dc voltage with magnitude up to $26 \mathrm{kV}$, and a grounded mesh was used as an opposite electrode. Different operational regimes of this corona generator were investigated for the production of ozone in air flow and the inactivation of microorganisms. The test microorganisms used in this work were Escherichia coli and Staphylococcus aureus, populations of which were seeded onto agar plates. These bacterial plates were located behind the grounded mesh electrode to assess bactericidal efficacy. The results show that corona discharges have a strong bactericidal effect, for example, positive flashing corona discharges were able to reduce populations of the test microorganism by $\sim 94 \%$ within a 30-60-s time interval. Negative steady-state corona discharges also produce noticeable bactericidal effect, reducing population of $E$. coli and $S$. aureus by more than $97 \%$ within a 120 -s energization interval. The bactericidal efficiency of different corona discharge modes and its correlation with ozone levels produced by these discharges are discussed. The results obtained in this work will help in the design and development of compact plasma systems for environmental applications.
\end{abstract}

Index Terms-Corona discharges, inactivation of microorganisms.

\section{INTRODUCTION}

C ORONA discharges in atmospheric air have been studied experimentally and theoretically over many decades. It has been shown that these discharges can be used for ozone generation [1]-[3], electrostatic precipitation [4], the removal of $\mathrm{NO}_{x}$ and $\mathrm{SO}_{2}$ from flue gas [5], the generation of ionic wind [6], and biological decontamination [7]. Currently, there is a growing interest in the practical applications of corona discharges for the generation and modification of gas flow and bacterial inactivation.

Biological action of nonthermal atmospheric pressure plasmas is a subject of intensive investigation aimed at the development of novel decontamination technologies and plasma-medical applications [8]-[13]. Nonthermal plasmas can be generated using ac or dc energization, and examples of practical plasma systems include atmospheric plasma jet topologies, dielectric barrier discharges (DBDs), and corona discharge topologies. The bactericidal effects of corona discharges have been studied in several papers [7], [14]-[18]; however, the

Manuscript received October 14, 2011; revised February 3, 2012; accepted March 22, 2012.

The authors are with the Department of Electronic and Electrical Engineering, University of Strathclyde, G1 1XW Glasgow, U.K. (e-mail: igor. timoshkin@eee.strath.ac.uk).

Digital Object Identifier 10.1109/TPS.2012.2193621 complete mechanism of the inactivation of the microorganisms is still unclear. Corona discharges are generally produced in geometries which produce highly divergent electric fields using high voltage (HV) electrodes with sharp edges or protrusions. If the magnitude of the applied voltage exceeds the corona inception value, intense ionization in the high field region results in the development of corona discharges. Ions generated in this ionization zone travel toward the opposite electrode through the drift region where the field is relatively low. Both positive and negative polarities can be used for the generation of corona discharges; however, their appearance and the behavior of the discharge current can be different.

Negative corona discharges in atmospheric air, which has electronegative properties due to the presence of oxygen, generate electrons in the ionization zone which travel toward the anode, leaving behind a narrow layer of the positive space charge near the cathode. This cathode sheath increases the electric field which supports ionization processes. Not all electrons are able to reach the anode; some of them attach to electronegative molecules, thus creating a volumetric negative space charge. This space charge screens the corona electrode, reducing the local field which suppresses the ionization processes. The electric field in the transport zone between electrodes moves negative ions toward the anode, this process results in the reestablishment of the high local electric field, ionization resumes, and the next current impulse is generated [19]. Such current impulses are called Trichel impulses [20]. With an increase in the applied negative voltage, the frequency (repetition rate) of the Trichel pulses increases as shorter times are required for the negative ions to drift toward the anode. Also, with an increase in the applied voltage, the dc current component starts to dominate, and the average current in the corona discharge is mainly defined by this dc component.

Positive energization of the corona electrode can lead to the formation of large current impulses with a magnitude significantly higher than the steady-state positive corona current. Such regime is called flashing corona discharge, and these current impulses are associated with the formation and development of positive streamers [17], [18], [21]. Current impulses are generated at voltages above the corona inception voltage and below the spark breakdown voltage. The rise time of these current impulses is linked to the ionization time at the cathode, where a narrow layer of positive ions develops due to charge separation and screens the anode field, thus resulting in suppression of ionization. The following current impulse will be generated after the removal of this positive charge layer by the electric field and the reestablishment of the high local anode field 
sufficient for ionization. Therefore, it can be said that Trichel impulses under negative conditions and flashing positive corona impulses are similar in nature as, in both cases, their development is associated with ionization and formation of positive and negative space charges. Repetition rate (frequency) of positive flashing corona impulses can reach tens of kilohertz, and the frequency of Trichel impulses can reach megahertz range [20].

The chemical composition of plasma generated by atmospheric pressure corona discharges in air is complex and is not fully understood. It is known that these discharges produce chemically active species: oxygen ions and other charged species such as $\mathrm{N}^{+}, \mathrm{NO}^{+}, \mathrm{NO}^{-}$, hydroxyl and hydroperoxyl radicals $\left(\mathrm{OH}\right.$ and $\left.\mathrm{HO}_{2}\right)$, hydrogen peroxide $\left(\mathrm{H}_{2} \mathrm{O}_{2}\right)$, nitrous oxide $\left(\mathrm{N}_{2} \mathrm{O}\right)$ and other nitrogen oxide species $\left(\mathrm{NO}, \mathrm{NO}_{2}\right.$, $\mathrm{N}_{2} \mathrm{O}_{4}$, and $\mathrm{N}_{2} \mathrm{O}_{5}$ ), and neutral species in their ground and excited states, including atomic oxygen, ozone, and oxygen molecules in the singlet state [22], [23].

In the case of negative corona, it was found that ozone is a dominant component among other oxygen species [25], [26], and in the case of positive corona discharges (in oxygen), it was found that ozone has the highest concentration after molecular oxygen [24]. In the negative corona discharges in air, super oxide anions, $\mathrm{O}_{2}^{-}$, are the main charge carriers which reach the anode [27]. In positive corona discharges in air, positively charged clusters, $\left(\mathrm{H}_{2} \mathrm{O}\right)_{n} \mathrm{H}^{+}$and $\mathrm{NO}^{+}\left(\mathrm{H}_{2} \mathrm{O}\right)_{n}$, have been registered by mass-spectroscopy technique [28]. Positive steadystate corona discharges in air normally generate less ozone as compared with negative corona at the same energization potential. In the case of corona discharges in confined space, the accumulation of chemical species in air may affect electrical characteristics of corona discharges [29].

Biological effects of corona discharges have been reported in the literature. For example, papers by Dobrynin et al. [7], Korachi et al. [14] and Machala et al. [17] discuss the inactivation of microorganisms by dc positive and negative corona discharges in different gases. It is believed that the main mechanism of the biological action of corona discharges is oxidative damage produced by reactive oxygen species (ROS) which are able to induce damage to biomolecules, including DNA and proteins. Reactive oxygen species also interact with lipids causing alterations in the functions of biological membranes. These factors can potentially lead to cell death. Dobrynin et al. [8] investigated the inactivation of Escherichia coli by dc corona discharges and concluded that the main mechanism of inactivation was the peroxidation of cell membranes. In these tests, bacteria were seeded onto grounded metallic agar plates, which were placed under a number of needle electrodes stressed with HV. Dobrynin et al. [8] argue that ultraviolet (UV) light and ozone generated by atmospheric plasma discharges were not the main bactericidal factors in their tests. The authors state that, in the case of direct discharges, the main bactericidal effect is achieved by the chemical action of ionic species (peroxidation of biological membranes). However, Korachi et al. [14] observed that corona discharges generated above Petri dishes filled with water contaminated with E. coli and Staphylococcus aureus do not cause significant changes in the fatty acid content of biological membranes. Fatty acid profiles remained saturated after corona treatment, and the authors concluded that exposure to these discharges does not produce free bonds to which $\mathrm{OH}$ radicals could attach. The attachment of $\mathrm{OH}$ radicals to unsaturated fatty acids induces lipid peroxidation and changes in membrane fluidity. The authors suggested that other potential mechanisms, including changes in function of the membrane's ionic channels, may be responsible for bacterial inactivation induced by corona discharges.

Ozone is a member of the ROS family and has a high oxidizing potential; thus, this agent may play an important role in biological cell inactivation by corona discharges. Fletcher et al. [16] studied HV inactivation of different bacteria and found that all tested microorganisms were susceptible to ozone produced in their multiple point-plane electrode system. Ozone can damage the membrane and induce cellular lysis, and it has been shown that even modest concentrations of ozone can result in the suppression of the proliferation of microorganisms. Leipold [30] used an afterglow of atmospheric plasma discharges for the decontamination of grapes in a fridge. The level of ozone in the plasma afterglow delivered into the fridge varied from 20 to $150 \mathrm{ppm}$, and the author found that $20 \mathrm{ppm}$ of ozone was enough to kill Botrytis fungal spores. Treatment of grapes with the plasma afterglow containing ozone produced results comparable with that of a traditional preservation method in which $\mathrm{SO}_{2}$ gas is used.

Another mechanism of the bioaction of corona discharges is UV radiation generated by these discharges; it is well documented that UV photons can cause significant damage to biological macromolecules, including DNA. Also, an electrostatic mechanism may potentially contribute to biological effects of corona discharges. The magnitude of electric field in the drift zone and in the vicinity of the ground electrode is significantly lower than the field in the corona ionization zone, and typically, the field alone is not sufficient to cause cell death. However, some microorganisms can potentially be more susceptible to electric fields than others; for example, Fletcher et al. [16] argue that electric field is a main factor which causes the inactivation of Mycobacterium parafortuitum in their multiple point-plane electrode system energized with HV. An analytical electrostatic analysis shows that electric fields exert mechanical forces on model microorganisms which may result in mechanical compression and rupture of biological membranes [31]. Electrostatic calculations also demonstrate that the integrity of the cell membrane can be broken by an electric field which is generated across the membrane due to the accumulation of ions on its surface when exposed to a nonthermal plasma [32].

There are two main topologies of corona discharge systems which are typically used in biological experiments: the direct and indirect topologies. In the direct method, the biological samples are located between the corona-generating and the grounded electrodes. In the indirect method, the biosamples are located behind the grounded electrode which is generally in the form of a metallic mesh. In the case of direct treatment, in addition to the electric field and UV radiation, samples are subjected to the charged and neutral chemically reactive species generated by corona discharges. With indirect treatment, the grounded metallic mesh screens biological samples from the direct action of the interelectrode electric field and charged particles (ions). However, neutral species are able to pass through the mesh 
and will react with the sample. The previous literature has reported on both the direct and the indirect bactericidal efficacy of corona discharges [7], [16], and opposite tendencies in inactivation results have been observed. While Dobrynin et al. [7] state that the inactivation efficiency for $E$. coli in the case of indirect treatment with mesh was low $(<1 \log$ reduction in $1 \mathrm{~min}$ ), another study [16] shows that the grounded mesh improved the inactivation rate of Pseudomonas aeruginosa and Burkholderia cenocepacia but noticeably reduced the inactivation efficiency of Acinetobacter baumannii and S. aureus. This difference between inactivation tendencies may be attributed to the significantly shorter exposure time, 1-2 min, used in [7], while the minimum and maximum exposure times in [16] were 5 and $15 \mathrm{~min}$, respectively. As indicated in [7], in the case of direct corona treatment, inactivation is a dose-dependent process, and the discussion of doses and corresponding inactivation efficiencies is given later in this paper. With the indirect method, zero or a minimum amount of charged particles will reach the biological sample; therefore, it is reasonable to assume that neutral chemically active species (predominantly ozone) play an important role in the inactivation process. Fletcher et al. [16] state that "for the most species tested, the negative ions and electric field played only a minor role in cell death compared with the action of ozone."

This paper focuses on the indirect inactivation of E. coli and S. aureus by corona discharges in air. E. coli and S. aureus were chosen as the test microorganisms because they are significant environmental and nosocomial pathogens [33]. Also, E. coli and $S$. aureus represent two of the main Gram-negative and Gram-positive bacterial species, respectively.

Bactericidal effects of the indirect corona discharges have been studied in this paper. This type of discharge eliminates the direct action of the charged particles on treated surfaces (agar plates in this study), as the grounded mesh protects the treated surface from plasma streamers and sparks, thus providing safe treatment conditions. The discharge current returns to the ground through the mesh. Indirect treatment may have advantages for the inactivation of bacteria on surfaces in cases where direct plasma contact with the treated surface should be avoided. This approach has similarities to that of barrier coronal discharges [12] in which the grounded mesh is used to avoid current passage to the treated surface (skin in the case of medical applications). It is known that direct corona discharges produce a stronger bactericidal effect as compared with indirect treatment, and a comparison of these two methods can be found in papers [7], [16]. However, the indirect method is of interest due to the safety issues discussed earlier.

The positive and the negative dc energization used in this study produced different regimes of corona discharges: negative discharges with Trichel impulses, positive steady-state and flashing coronas. Plastic agar plates seeded with E. coli and $S$. aureus bacteria were located behind the grounded metallic mesh in the sealed test system and exposed to differing durations of discharge treatment. It is known that ozone is one of the main oxygen species produced by nonthermal plasma discharges in air [24], [26], and in this study following [34], ozone is used as an indicator of ROS production in corona discharges. Ozone concentration was monitored by an in-line ozone meter,

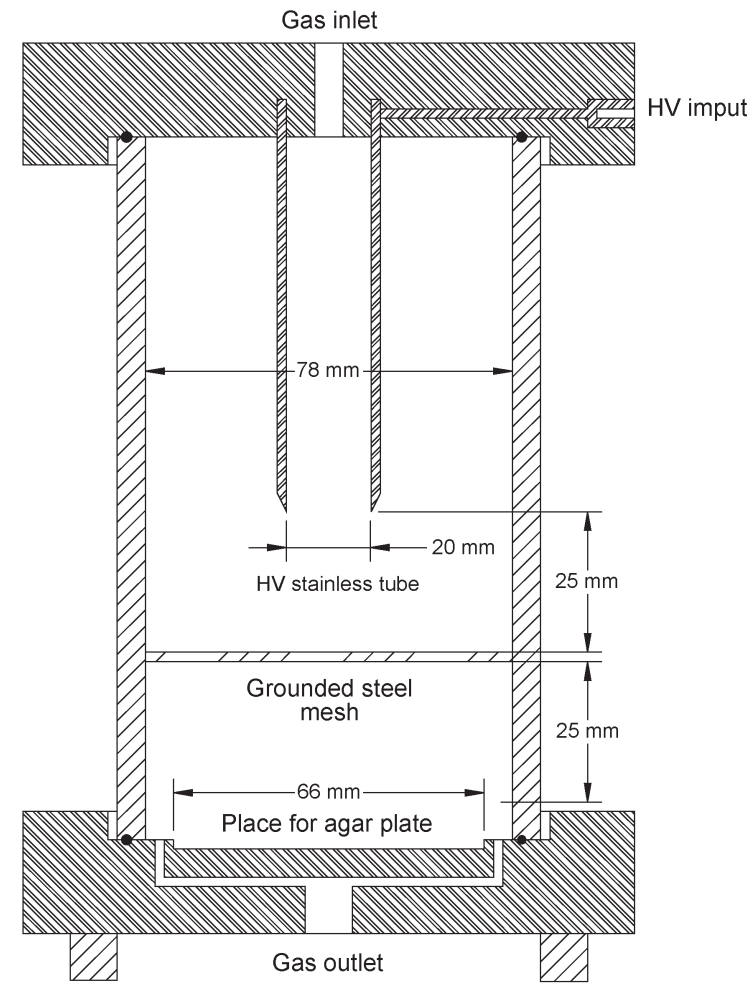

Fig. 1. Test cell for indirect corona treatment.

and correlation between measured ozone concentrations and the inactivation efficiency of corona discharges is discussed.

\section{EXPERIMENTAL SYSTEM}

A system for the investigation of the indirect bactericidal action of corona discharges has been developed. The test cell has been made of a Perspex cylinder of 78-mm diameter, with two PVC flanges used to seal the top and bottom of the cylinder. Flexible gas tubes with an external diameter of $4 \mathrm{~mm}$ were used to deliver gas (air) into, and to remove gas out of, the test cell. Push-in fittings for the gas tubes were centrally located in the flanges. Air was injected into the internal cavity of a tubular stainless steel corona electrode (20-mm diameter), and the edge of this electrode was sharpened to provide optimal conditions for ignition of corona discharges. The corona electrode was energized with positive and negative voltages produced by Glassman dc power supplies connected to the test cell through the current-limiting resistor.

Steel mesh was inserted into the test cell, with a distance of $25 \mathrm{~mm}$ being maintained between the edge of the tubular HV electrode and the mesh. Plastic agar plates with a diameter of $66 \mathrm{~mm}$ were located at a distance of $25 \mathrm{~mm}$ under the mesh. This topology was used in all experiments described in this paper. The gas used in the present tests was atmospheric air and compressed bottled air provided by BOC, with gas being delivered into the test cell through a gas distribution board. Constant gas pressure slightly above atmospheric (0.2 bar for bottled air and 0.3 bar for atmospheric air) was kept in the test cell. The exhaust gas was passed through an inline ozone analyzer (IN-2000 LoCon, IN USA) which allowed monitoring of ozone concentrations. This ozone analyzer has an internal ozone destruction unit which removes ozone from the 

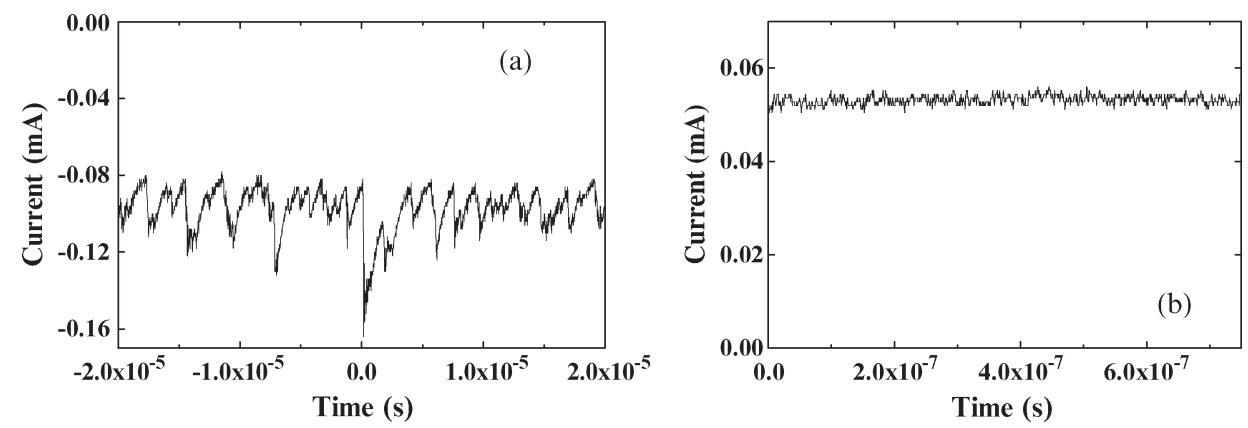

Fig. 2. (a) Negative and (b) positive corona current waveforms in atmospheric air at 0.3 -bar gauge. The stress voltage: (a) $-26 \mathrm{kV}$ and (b) $+26 \mathrm{kV}$.

sample gas and then subtracts the absorbance measured in this reference channel from the absorbance measured in the channel without destructor. Thus, possible interference from other gases is removed from measurements. A schematic diagram of the test cell is shown in Fig. 1.

Electrical diagnostic devices include a dc HV probe (TES-TEC HVP-40) attached to the output terminal of the current-limiting resistor, in combination with a digital multimeter which was used to monitor the voltage applied to the corona electrode. The metallic mesh was grounded through a $1-\mathrm{k} \Omega$ current viewing resistor which allowed current waveforms to be obtained and recorded using a digitizing oscilloscope Tektronix TDS 3032.

The test microorganisms used in this study were E. coli NCTC 9001 and S. aureus NCTC 4135, obtained from the National Collection of Type Cultures (Collindale, U.K.). For experimental use, E. coli and S. aureus were inoculated into 100 -mL nutrient broth and cultivated at $37{ }^{\circ} \mathrm{C}$ for $18 \mathrm{~h}$ under rotary conditions. The broth was then centrifuged $(4300 \mathrm{r} / \mathrm{min}$ for $10 \mathrm{~min}$ ), and the resultant pellet was resuspended in $100-\mathrm{mL}$ phosphate buffered saline and serially diluted to a population of $10^{3} \mathrm{CFU} / \mathrm{mL}$. For discharge treatment within the test cell, $E$. coli and $S$. aureus were seeded onto agar plates by spreading $100 \mu \mathrm{L}$ of the bacterial suspension on the agar surface, giving approximately 200 colony forming units (CFUs) per plate (CFU/plate). Control plates were also set up which were held within the test chamber for the desired treatment time, but without the HV applied to the corona-generating electrode. Posttreatment plates were incubated at $37^{\circ} \mathrm{C}$ for $18 \mathrm{~h}$ and then enumerated.

\section{Positive Steady-State and Negative Trichel-LiKe Corona Discharges}

\section{A. Electrical Parameters of Corona Discharges}

Atmospheric air with a relative humidity of $\sim 50 \%$ was delivered into the test cell using an air compressor, FIAC FX95. The pressure in the test cell was kept slightly above atmospheric pressure, 0.3-bar gauge. Three levels of positive and negative voltages were used in these tests: 22, 24, and 26 $\mathrm{kV}$. In the case of negative energization, the observed current waveforms for all voltage levels were a superposition of two components: dc corona current and Trichel current impulses. The main contribution to the total (average) negative corona current is made by the dc current component, and this negative corona current will be referred to as a Trichel-like current. In the

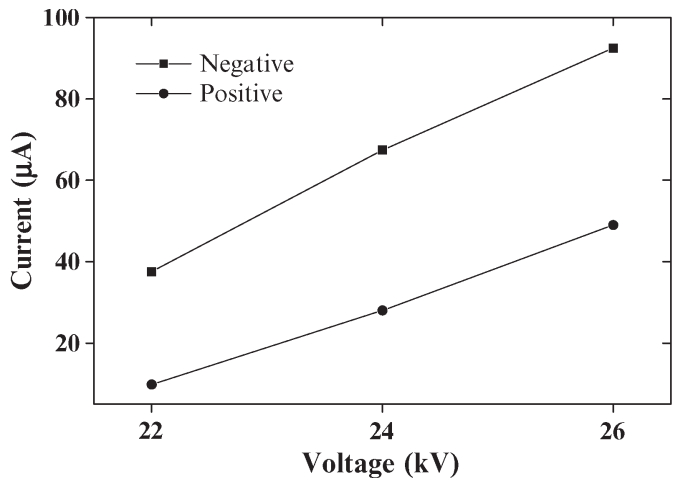

Fig. 3. $V-I$ curves for positive and negative corona discharges in atmospheric air, with 0.3-bar gauge pressure.

case of positive energization, a steady-state corona current was observed for all three voltage levels. Typical current waveforms are shown in Fig. 2.

Voltage-current characteristics of corona discharges in atmospheric air (pressure of 0.3-bar gauge) are shown in Fig. 3.

Average values for negative current have been calculated: Current waveforms have been integrated over the recorded time intervals, and then, obtained charge values have been divided by these intervals. These $V-I$ curves are close to straight lines, which could be explained by the relatively narrow voltage range used in the present tests: It is expected to observe a spacecharge-limited behavior for $V-I$ curves for a wider voltage range. Fig. 3 shows that the steady-state positive corona current is lower than the negative corona current; in both cases, the current does not exceed $100 \mu \mathrm{A}$.

\section{B. Microbiological Effects of Positive Steady-State and Negative Trichel-Like Corona Discharges}

Agar plates seeded with E. coli and S. aureus were positioned behind the grounded mesh of the test cell in order to assess the indirect bactericidal efficacy of the steady-state corona discharges. It was expected that the airflow would push chemically active species produced by the corona discharges toward the agar plates through the mesh; however, the majority of the charged species should be extracted from the flow by the grounded mesh electrode.

Bacterial agar plates were exposed to indirect corona action for $15,30,60$, and $120 \mathrm{~s}$ in order to observe inactivation kinetics. Ozone levels produced by the corona discharges were also monitored by the in-line ozone analyzer. Results of these inactivation tests are shown in Figs. 4 and 5, and each point 

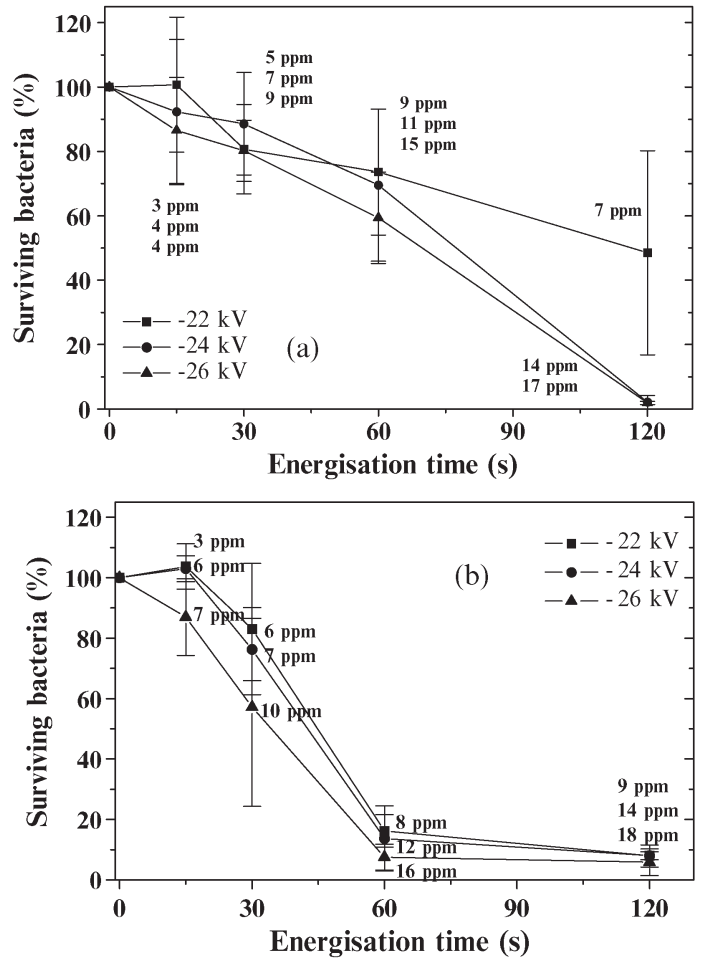

Fig. 4. Indirect bactericidal effect of corona discharges (negative energization). (a) and (b) show results for E. coli and S. aureus, respectively. Values in parts per million are average ozone levels for each voltage level.
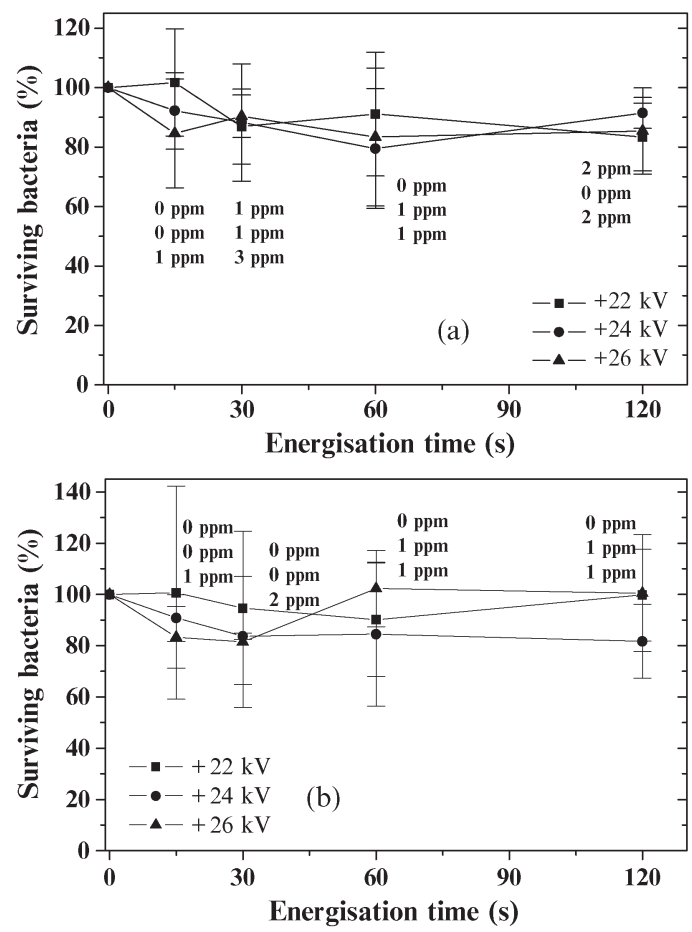

Fig. 5. Indirect bactericidal effect of corona discharges (positive energization). (a) and (b) show results for E. coli and $S$. aureus, respectively. Values in parts per million are average ozone levels for each voltage level.

in these figures represents an average over three independent tests. Error bars show standard deviation values. Fig. 4 shows the surviving fractions of both types of microorganisms and the values of ozone in parts per million in the case of corona discharges driven by three different dc voltages.
It can be observed from these graphs that the indirect bactericidal effect depends on the level of ozone and the exposure time. For E. coli, this effect was maximal, $298 \%$, for 2-min energization at two voltage levels, $-24 \mathrm{kV}$ and $-26 \mathrm{kV}$, which generated 14-17 ppm of ozone. S. aureus is more sensitive to the indirect corona discharge treatment: Maximal bactericidal effect, $\sim 86 \%-93 \%$, for $-24-\mathrm{kV}$ and $-26-\mathrm{kV}$ voltage levels has been achieved by 1-min energization. The level of ozone changes with the magnitude of the voltage and current.

Fig. 5 shows the inactivation of E. coli and $S$. aureus in the case of dc positive energization. Maximum concentrations of ozone produced by positive steady-state corona discharges are significantly lower than ozone concentrations generated by negative corona discharges, for example, $0-2 \mathrm{ppm}$ versus $7-18 \mathrm{ppm}$ for a 2-min exposure. As a result, positive steady-state corona discharges produced significantly lower bactericidal effects as compared with the indirect action of negative corona discharges: After a 2-min exposure to positive discharges driven by $+24 \mathrm{kV}$ and $+26 \mathrm{kV}, \sim 82 \%-100 \%$ of both types of bacteria survived, while in the case of negative discharges driven by $-24 \mathrm{kV}$ and $-26 \mathrm{kV}$, less than $2 \%$ of $E$. coli and $\sim 6 \%-8 \%$ of $S$. aureus survived.

In order to make a relative comparison with other published data [7], apparent doses can be calculated by dividing the total charge (which is the average current multiplied by exposure time) by the surface area of the agar plate. The maximum apparent dose in the case of positive energization is $\sim 1.7 \mathrm{C} / \mathrm{m}^{2}$ (+26 kV and 2-min exposure time). This dose does not produce a noticeable bactericidal effect; however, a slightly lower apparent dose of $\sim 1.6 \mathrm{C} / \mathrm{m}^{2}$ in the case of negative energization ( $-26 \mathrm{kV}$ and 1-min exposure time) resulted in $\sim 93 \%$ inactivation of $S$. aureus and $\sim 40 \%$ inactivation of E. coli (see Fig. 4). This observation indicates that bactericidal efficiency of indirect treatment does not depend on apparent dose linearly; other factors such as the concentration of ozone (and, potentially, other reactive species) and treatment time should be taken into account. The "apparent dose" values do not represent the actual charge which is delivered into the agar plates as in the case of direct treatment, and these apparent doses are provided for evaluation purposes only.

\section{Negative TRICHel-Like AND POSITIVE FLASHING CORONA}

\section{A. Electrical Parameters of Corona Discharges}

In another set of experiments, bottled compressed air was used as a working medium for corona discharges, with the pressure in the test cell held at a 0.2-bar gauge in order to promote a flashing regime of positive corona discharges. The relative humidity of bottled air was $\sim 5 \%$. These conditions changed the appearance of positive corona discharges, while in the case of negative corona, the Trichel regime has been observed.

Observed current waveforms for negative corona discharges were a superposition of steady-steady current and Trichel impulses as before. Slightly higher average values for the negative current have been obtained as compared with those described in Section III-A due to lower pressure in the test 

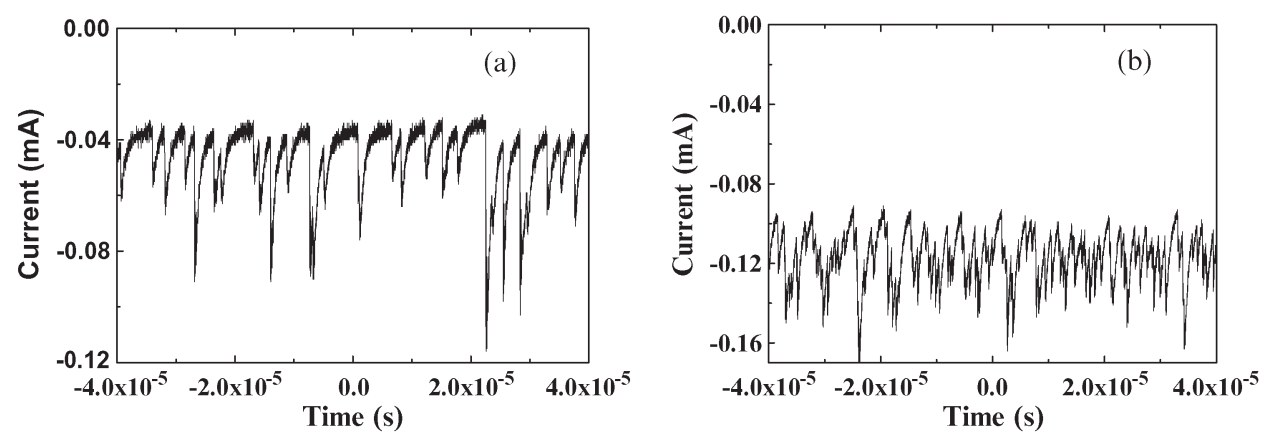

Fig. 6. Current waveforms of negative corona in bottled air at 0.2-bar gauge pressure. (a) $-22 \mathrm{kV}$. (b) $-26 \mathrm{kV}$.
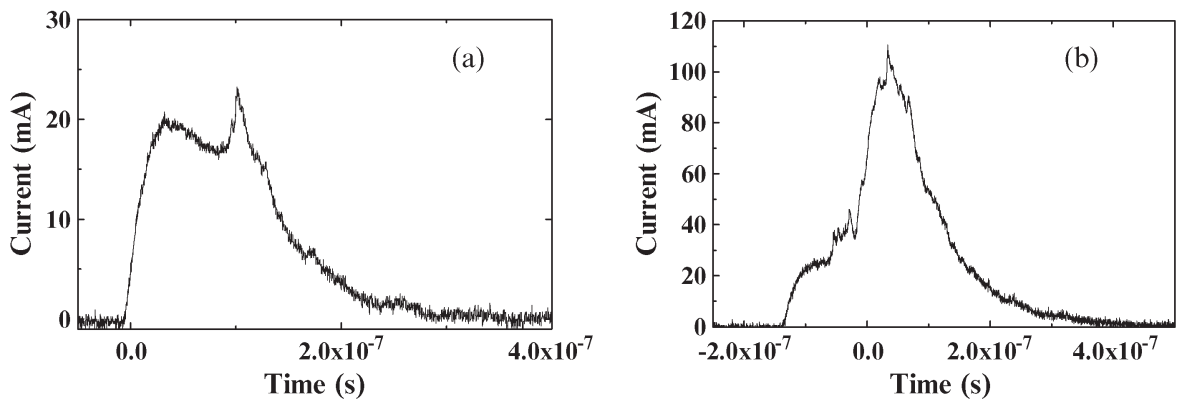

Fig. 7. Current impulses observed in the case of positive flashing corona in bottled air at 0.2 -bar gauge pressure. (a) $+22 \mathrm{kV}$. (b) $+26 \mathrm{kV}$.

cell. Trichel impulses have a relative magnitude of a few tens of microamperes $(\sim 20-60 \mu \mathrm{A})$, and the frequency of Trichel impulses depends on the magnitude of the applied dc voltage. Typical current waveforms of negative corona discharges in bottled air (0.2-bar gauge pressure) for $-22 \mathrm{kV}$ and $-26 \mathrm{kV}$ are shown in Fig. 6. The frequency of Trichel impulses was in the range of $\sim 25 \cdot 10^{4}$ pulses/s and $\sim 55 \cdot 10^{4}$ pulses/s, depending on the voltage magnitude.

Positive corona discharges in these conditions had a flashing character: Current impulses with a duration of 200-300 ns and a peak magnitude of tens/hundreds of milliamperes were superimposed on relatively low steady-state current (tens/ hundreds of microamperes).

Positive flashing impulses are not stable, and their frequency and appearance depend strongly not only on the level of driving voltage but also on the gas parameters in the test cell. For example, the energization of the corona electrode with $+26 \mathrm{kV}$ generated flashing current impulses with a magnitude up to $\sim 100 \mathrm{~mA}$ and a frequency of $\sim 5 \cdot 10^{4}$ pulses/s. Typical waveforms of positive flashing impulses generated by $+22-\mathrm{kV}$ and $+26-\mathrm{kV}$ voltages are shown in Fig. 7.

The regime of flashing positive corona used in this paper is similar to the "transient spark" regime observed in [17], in which Machala et al. describe submicrosecond current impulses with a magnitude of $\sim 18$ A generated in atmospheric air in the point-plane electrode topology stressed with a positive dc voltage $(+13 \mathrm{kV})$. The frequency of these impulses was in the range of $0.5-10 \mathrm{kHz}$. Using optical emission spectroscopy, the authors showed that "transient spark" discharges generate atomic oxygen, nitrogen and hydrogen radicals, nitrogenexcited species, ions, and ozone. The authors conclude that the ROS, including ozone, atomic oxygen, and $\mathrm{OH}$ radicals, play a main role in the inactivation of microorganisms by

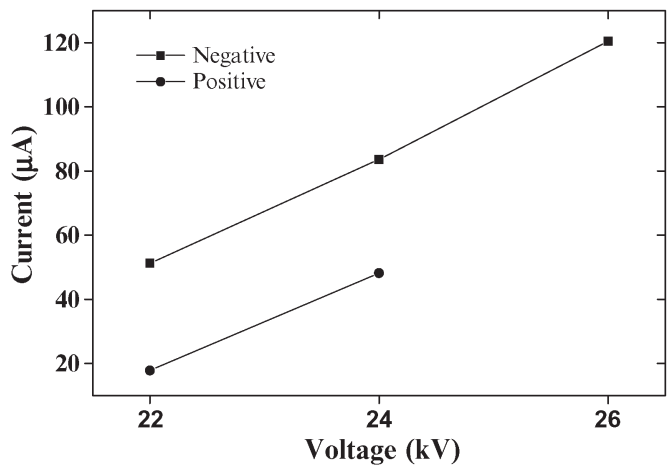

Fig. 8. $\quad V-I$ characteristics of negative corona and flashing positive corona in bottled air at 0.2 -bar gauge pressure.

the transient sparks and streamer corona discharges. In [17], Salmonella typhimurium was used as a test microorganism. Although Machala et al. [17] do not provide numerical values of inactivation efficiency, based on the visual appearance of agar plates shown in this paper, it is possible to conclude that direct treatment is more efficient as compared with indirect corona discharge treatment.

It has been noted in this paper that the introduction of wet agar plates in the test cell could significantly influence the characteristics of the positive corona discharges. This effect was unexpected as agar plates were located relatively far behind the grounded mesh electrode. However, due to the turbulent motion of air in the test cell, water vapor can be transported into the ionization zone, resulting in different modes of corona discharges as compared with positive discharges in the empty test cell.

Fig. 8 presents the $V-I$ characteristics of negative and positive corona discharges obtained in the case of bottled air and 0.2-bar gauge pressure. 

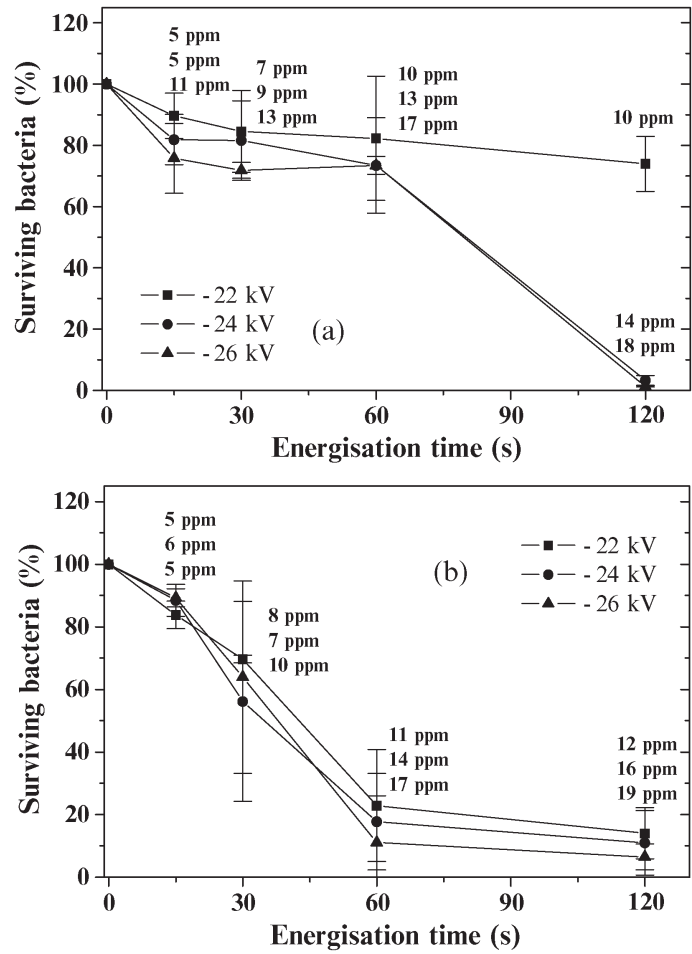

Fig. 9. Indirect bactericidal effect of negative corona discharges in bottled air at 0.2-bar gauge. (a) and (b) show results for E. coli and S. aureus, respectively. Values in parts per million are average ozone levels for each voltage level.

Negative current values have been calculated as integral average values. However, it was difficult to obtain an average current value for positive flashing discharges: The frequency of flashing impulses was unstable, and due to a three-order-ofmagnitude difference in the peak impulse current and steadystate current between these impulses, it was not possible to monitor both values simultaneously. An average current was evaluated by multiplying the integral average of current derived for individual flashing impulses by the frequency of these impulses. In separate tests, the steady-state current between the flashing impulses was measured, and then, both values were added together. It has been estimated that, in the present conditions, the steady-state current components for $+22 \mathrm{kV}$ and $+24 \mathrm{kV}$ were larger than the cumulative flashing impulsive current, and these current values are shown in Fig. 8. However, in the case of a $+26-\mathrm{kV}$ stress voltage, the flashing current component was dominant in the total average current, which has a magnitude of $0.73 \mathrm{~mA}$ and not shown in Fig. 8.

\section{B. Bactericidal Effects of Trichel-Like Negative and Flashing Positive Corona Discharges}

E. coli and S. aureus bacteria seeded on agar plates were also used in this study of indirect bactericidal effects of negative steady-state and positive flashing corona discharges. As in the tests described previously, ozone concentration was monitored during corona treatment.

Fig. 9 shows the indirect inactivation curves for E. coli and $S$. aureus in the case of negative corona discharges. Trichellike negative corona current with bottled air at a 0.2-bar gauge was slightly higher as compared with the corona discharges in
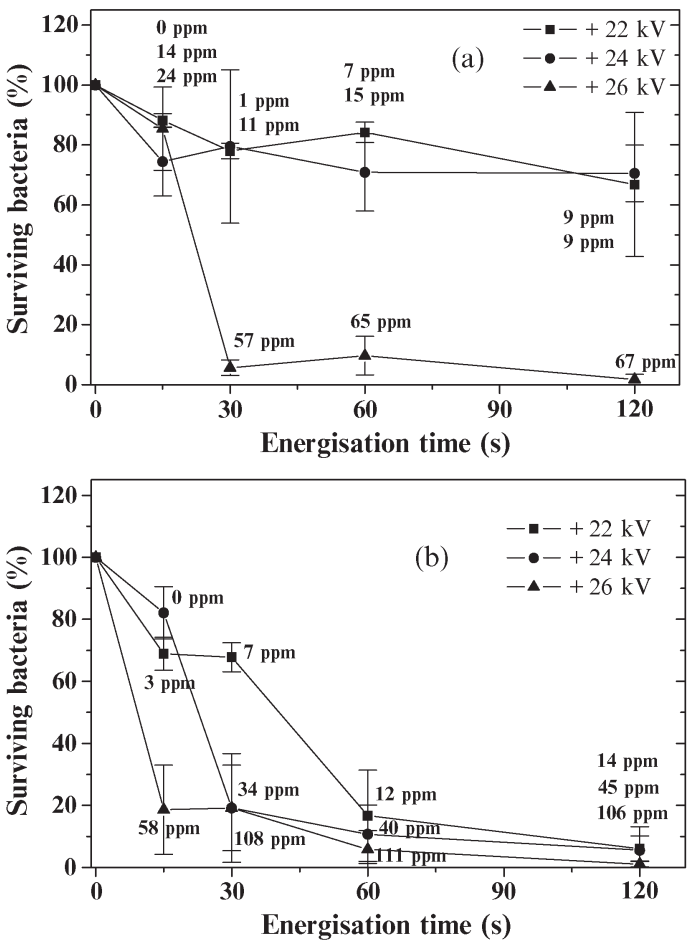

Fig. 10. Indirect bactericidal effect of positive corona discharges in bottled air at 0.2-bar gauge. (a) and (b) results for E. coli and S. aureus, respectively. Values in parts per million are average ozone levels for each voltage level.

atmospheric air at a 0.3-bar gauge. For example, for $-26-\mathrm{kV}$ energization, the average negative currents were $\sim 120 \mu \mathrm{A}$ and $\sim 93 \mu \mathrm{A}$. However, the ozone concentrations were almost the same, reaching 19 and $18 \mathrm{ppm}$ for 2-min exposure using bottled air at a 0.2-bar gauge and atmospheric air at a 0.3-bar gauge, respectively.

As a result of these factors, the inactivation efficiency of the negative corona discharges shown in Fig. 9 is similar to the efficiency shown in Fig. 4: A 2-min exposure at the energization level of $-26 \mathrm{kV}$ resulted in almost complete inactivation of E. coli, 1.3\% survived bacteria, as shown in Fig. 9(a). S. aureus was more sensitive to the indirect corona treatment: Almost $\sim 89 \%$ of this type of bacteria were killed by 1-min corona action driven by $-26 \mathrm{kV}$, as shown in Fig. 9(b).

Positive dc energization generated flashing corona current, and the corresponding inactivation results are shown in Fig. 10.

There is a significant difference between the bactericidal efficiency of the steady-state positive corona discharges (see Fig. 5) and the flashing corona discharges. Thirty seconds of indirect exposure to the flashing corona discharges, driven by $+26 \mathrm{kV}$, resulted in significant inactivation, reducing populations of E. coli down to $\sim 6 \%$ and $S$. aureus down to $\sim 19 \%$. This regime of corona discharges produces high ozone levels, in the range between 57 and 108 ppm. Higher levels of ozone production can be attributed to the higher average current: $730 \mu \mathrm{A}$ as compared with $49 \mu \mathrm{A}$ for steady-state corona discharges at the same voltage level. Moreover, the peak current in each individual impulse is significantly higher than the average current, for example, for $+26 \mathrm{kV}$, the peak current is $100 \mathrm{~mA}$ compared to tens/hundreds of microamperes of the average current. Normally, voltages of $+22 \mathrm{kV}$ and $+24 \mathrm{kV}$ 
generated only steady-state dc corona discharges with lower average currents, (9.8 and $28 \mu \mathrm{A}$, respectively) and, as a result, significantly lower ozone levels. However, current impulses have been observed in the tests with $S$. aureus in the case of the $+22-\mathrm{kV}$ and the $+24-\mathrm{kV}$ energization. These impulses resulted in the production of higher ozone levels as compared with the steady-state dc current and higher inactivation effect, as shown in Fig. 10(b). Figs. 9 and 10 show that increased inactivation efficiency tends to follow the increased ozone concentration produced by corona discharges.

In order to evaluate the potential toxicity of agar subjected to the indirect action of corona (for example, due to possible changes in the level of $\mathrm{pH}$ or concentration of hydrogen peroxide), agar plates with no microorganisms were subjected to positive and negative discharges in both steady-state and flashing regimes. After that, microorganisms were seeded onto treated agar plates and control agar plates (no corona indirect treatment). Numbers of CFU/plate were compared for treated and untreated agar plates.

No difference in CFU numbers has been registered, and the conclusion has been made that this indirect corona treatment does not cause toxic changes in agar. Therefore, potentially, ozone is the main agent which produces strong bactericidal action observed in the present study. However, further study of other chemically active species generated by corona discharges is necessary in order to evaluate their potential contribution into indirect inactivation.

\section{Discussion AND CONCLUSion}

\section{A. Main Results}

The indirect bactericidal action of the dc energized corona discharges in air has been studied. The results of this work have demonstrated that both positive and negative corona discharges can indirectly inactivate $E$. coli and $S$. aureus. The inactivation efficiencies of the steady-state and flashing corona discharges have been examined. It has been observed that the negative energization of the corona electrode generates steady-state discharges with reproducible current waveforms and ozone levels. Ozone has been chosen as an indicator of the ROS production in corona discharges in atmospheric air, and correlation between ozone concentrations and inactivation has been observed. However, potentially, other chemically active species produced by these discharges (such as nitric oxide and others) may contribute to the inactivation of microorganisms. Ozone levels depend on the magnitude of the voltage and energization time: In the present study, ozone levels in the range from 3-7 ppm (15-s energization time) to 7-18 ppm (120 s) have been registered for $-22,-24$, and $-26 \mathrm{kV}$. The indirect inactivation effect of the negative dc corona discharges was also reproducible for both species of microorganism. It has been observed that $S$. aureus is more sensitive to such indirect corona action: A 60-s energization time resulted in $\sim 93 \%$ inactivation of this microorganism in atmospheric air (16 ppm of ozone) and $\sim 89 \%$ inactivation in bottled air (17 ppm), while the degree of inactivation of $E$. coli was $\sim 40 \%$ in atmospheric air (15 ppm of ozone) and $\sim 27 \%$ in bottled air (17 ppm). However, longer energization time (120 s) leads to almost complete kill of both microorganisms. Positive energization of the corona electrode can generate both steady-state discharge and flashing corona impulses. Positive steady-state discharges are characterized by significantly lower ozone concentrations as compared with the flashing corona regime. As a result, a low inactivation effect has been observed in the case of positive steady-state corona discharges, while as the positive flashing corona discharge activity increases, the indirect inactivation efficiency increases substantially. High magnitude current flashes in the positive flashing corona regime resulted in a substantial increase in apparent doses and higher ozone levels as compared with the steady-state positive and negative coronas. A high degree of inactivation has been achieved after a short 30-s energization time for both species of bacteria in the positive flashing corona regime. Therefore, this type of discharge has the potential to be developed for the rapid inactivation of microorganisms located on surfaces or suspended in air.

\section{B. Efficiency of Inactivation}

This section presents a comparison of the inactivation results obtained in the present study with the literature data. In [7], a study of the inactivation efficiency of dc positive and negative corona discharges in room air with $\sim 60 \%$ relative humidity was conducted. The authors used both direct and indirect corona treatments to inactivate E. coli on agar surfaces held in aluminum plates. Dobrynin et al. [7] report a substantial reduction in the number of CFUs in the case of direct corona treatment, and this inactivation effect depended on the charge dose, $\mathrm{C} / \mathrm{m}^{2}$. However, in the case of indirect treatment, the authors did not observe significant inactivation. For example, exposure to the maximum dose used in the indirect tests, $3 \mathrm{C} / \mathrm{m}^{2}$, resulted in an approximately twofold reduction of CFU for negative energization ( $\sim 50 \%$ inactivation) and a slightly less than twofold reduction for positive energization. In the case of direct exposure, negative energization produced an $\sim 1300$-fold reduction of CFU ( 99.93\% inactivation). Dobrynin et al. [7] do not provide inactivation efficiency for this dose in the case of positive energization; however, more efficient positive corona treatment with a lower dose of $2.25 \mathrm{C} / \mathrm{m}^{2}$ resulted in a higher $\sim 4000$ fold reduction in the number of CFUs counted on the plate ( $\sim 99.97 \%$ inactivation). Negative energization was less efficient: An 400-fold reduction in the number of CFUs counted on the plate was achieved for this dose ( $\sim 99 \%$ inactivation).

The apparent charge dose used in the present study varies from $0.04 \mathrm{C} / \mathrm{m}^{2}$ to $\sim 4.2 \mathrm{C} / \mathrm{m}^{2}$ for steady-state and Trichellike discharges and up to $\sim 25.6 \mathrm{C} / \mathrm{m}^{2}$ for flashing corona discharges, depending on polarity, air type, pressure in the test cell, and duration of corona treatment. The inactivation effect of indirect treatment observed in this study is higher as compared with the indirect inactivation reported in [7]. For example, in the case of the treatment of E.coli by negative indirect corona discharges in atmospheric air, treatment with $-24 \mathrm{kV}$ and $-26 \mathrm{kV}$ during 2 min (apparent doses of $\sim 2.4 \mathrm{C} / \mathrm{m}^{2}$ and $\sim 3.2 \mathrm{C} / \mathrm{m}^{2}$, respectively) resulted in $\sim 98 \%$ inactivation [see Fig. 4(a)]. In the case of corona discharges in bottled air, a similar regime of treatment with $-24 \mathrm{kV}$ and $-26 \mathrm{kV}$ during 2 min 
(apparent doses of $\sim 2.9 \mathrm{C} / \mathrm{m}^{2}$ and $\sim 4.2 \mathrm{C} / \mathrm{m}^{2}$, respectively) resulted in $\sim 96.7 \%$ and $\sim 98.7 \%$ inactivation, respectively [see Fig. 9(a)]. In the case of positive energization in bottled air with intensive current flashes, a maximum apparent dose of $\sim 25.6 \mathrm{C} / \mathrm{m}^{2}(+26 \mathrm{kV}$ and $2 \mathrm{~min})$ resulted in $\sim 98 \%$ inactivation [see Fig. 10(a)]. The maximum apparent dose achieved in the case of positive energization in atmospheric air was $\sim 1.7 \mathrm{C} / \mathrm{m}^{2}$ (steady-state corona discharges $+26 \mathrm{kV}, 2$-min exposure time, and no current flashes). Such regime of treatment resulted in a low inactivation efficiency of $14.6 \%$ and produced $2 \mathrm{ppm}$ of ozone [see Fig. 5(a)]. These results show that different regimes of corona discharges have different efficiencies for the production of ozone. Flashing coronas are more efficient in the generation of ozone and, potentially, other reactive species and produce greater inactivation efficiency.

The production of ozone has not been optimized in the present study. The maximum ozone yield achieved in this paper is $\sim 1 \mathrm{~g} / \mathrm{kWh}$, while in the case of optimized impulsive corona discharges in atmospheric air with a relative humidity of $13 \%-18 \%$, the maximum ozone yield is $105 \mathrm{~g} / \mathrm{kWh}$ [34]. The lower inactivation efficiency of indirect treatment in the study by Dobrynin et al. [7], as compared with the results obtained in this paper, can be potentially explained by several factors. In [7], the authors report that they used the same corona current $(0.1 \mathrm{~mA})$ in all experiments; therefore, it is reasonable to suggest that the regime of positive corona used in [7] was a steady-state corona with no current flashes. Also, the initial populations of $E$. coli used in [7] were significantly larger, $\sim 13000 \mathrm{CFU} /$ plate (in the case of indirect treatment), as compared with the present study, $\sim 200 \mathrm{CFU} /$ plate. Therefore, it is reasonable to assume that higher initial microbial populations require higher doses to achieve the same inactivation effect.

Fletcher et al. [16] reported the results of inactivation of different microorganisms, including $S$. aureus, by direct and indirect corona discharge treatments. The authors did not specify the diameter of agar plates used in their study; therefore, it is impossible to directly compare the inactivation efficiencies using charge doses, $\mathrm{C} / \mathrm{m}^{2}$. The authors of [16] investigated the bactericidal efficiency of direct treatment for both positive and negative polarities (which produced 0.8 and $2.3 \mathrm{ppm}$ of ozone, respectively); however, indirect treatment was conducted using only negative polarity. The initial concentration of microorganism in [16] was similar to the concentrations used in this paper, $300 \mathrm{CFU} /$ plate. The authors of [16] provided average values of the corona current in each case: Higher currents have been registered for negative energization $(65-114.3 \mu \mathrm{A})$ as compared with positive energization $(27-42.3 \mu \mathrm{A})$. Also, Fletcher et al. [16] report that the corona current was different for plates with different microorganisms which was attributed to variations in their experimental conditions: humidity of agar and air, air temperature, and air movement.

Therefore, in order to make a comparison with the present results, it is necessary to evaluate the total charge delivered by the corona discharges per plate. In [16], for negative energization $(-10 \mathrm{kV})$ with S. aureus, the total charge for a 15-min treatment was $585 \mu \mathrm{C} /$ plate [16]. This treatment resulted in $96 \%$ inactivation efficiency in the case of direct corona discharges and $46 \%$ in the case of indirect corona discharges. In this paper, similar values of charge/plate have been used for $S$. aureus treatment with negative corona discharges generated by the $-22-\mathrm{kV} \mathrm{HV}$ stress over $15 \mathrm{~s}$. In atmospheric air, the apparent charge value was $562.5 \mu \mathrm{C} /$ plate, and in the case of bottled air, the apparent charge was $768 \mu \mathrm{C} /$ plate. However, the inactivation efficiencies of these apparent charges were lower as compared with the results reported by Fletcher et al. [16]: No inactivation was observed in atmospheric air, and $16.2 \%$ inactivation was achieved in bottled air for the higher charge/plate value. These results suggest that exposure time may be an important factor in the corona inactivation process: The duration of corona treatment described in [16] was 60 times longer as compared with the present study for the doses discussed earlier.

In [14], a wire electrode located vertically above a water sample with microorganisms and stressed with positive HV was used as a discharge source, producing a narrow discharge channel with a diameter of $\sim 1 \mathrm{~mm}$. The charge carriers pass through the water sample, and the discharge current returns to the ground through another horizontally located wire submerged in water which fills this plate. This approach differs from volumetric corona discharges discussed in this paper, and the current density in the discharge channel is significantly higher than the charge/plate or charge $/ \mathrm{m}^{2}$ values discussed earlier. The microbiological data presented in [14] do not allow calculations of the inactivation efficiency as no initial concentrations of microorganisms have been provided, although the authors state that 2 min of plasma treatment was sufficient to kill both E. coli and S. aureus in the tests described in [14], and the corresponding total charge per plate with water sample was $10.8 \mathrm{C} /$ plate, which is high as compared with a few hundreds of $\mu \mathrm{C} /$ plate used in this paper and in [16].

\section{Possible Mechanism of Action}

Nonthermal plasma discharges in atmospheric air generate a variety of reactive species, including oxygen and nitrogen species. It is known that corona discharge, which is a kind of nonthermal plasma discharge, produces ROS, ozone, hydroxyl peroxide, nitrogen, hydrogen and $\mathrm{OH}$ radicals, and other chemically active species [23], [34].

Reactive species produced by nonthermal plasma in air induces stress on the membranes, proteins, lipids, and DNA of microorganism which can result in their death [9]. Ozone generated by the corona discharges can partially dissociate in waterbased biomaterials, generating oxygen molecules and atomic oxygen which can react with different available biomolecules to produce $\mathrm{OH}$ and other radicals, stimulating oxidation reactions in microorganisms [5]. Although most of the ROS can potentially cause oxidative damage to microorganisms, resulting in their death [23], the exact mechanisms of the bactericidal action of nonthermal plasmas are still unclear and require further investigation. Ozone and nitric oxides which are produced by atmospheric pressure plasmas are regarded as toxic gases [35]. The ozone production can be blocked by higher concentrations of nitric oxides (the discharge "poisoning" effect [5], [36]). This complex picture of production of reactive oxygen and nitrogen species in atmospheric plasma becomes even more complicated if the interaction of plasma with water is involved 
This article has been accepted for inclusion in a future issue of this journal. Content is final as presented, with the exception of pagination.

in the plasma-chemical processes. The presence of water vapor in atmospheric nonthermal plasma reduces the yield of ozone due to the generation of $\mathrm{OH}$ and $\mathrm{HO}_{2}$ radicals which interact and destroy $\mathrm{O}_{3}$ molecules [5]. In this paper, bottled air and atmospheric air have been used, and these gases have significantly different humidities, $\sim 5 \%$ and $\sim 50 \%$, respectively, as discussed earlier. However, nonlaminar air flow in the test cell and the potential evaporation of water from agar plates may change the local humidity inside the cell. The grounded mesh which is used in the case of indirect corona discharge treatment prevents the majority of the charged particles from reaching the surface of agar. Therefore, only neutral species generated by the corona discharges will interact with microorganisms seeded on the agar plates. Among these are oxygen- and nitrogen-based neutral species (mentioned earlier), ozone, atomic oxygen, singlet oxygen, hydrogen peroxide, $\mathrm{OH}, \mathrm{NO}$, and $\mathrm{NO}_{2}$ radicals.

The direct treatment of water with nonthermal atmospheric plasma discharges generates elevated concentrations of hydrogen peroxide which can result in more efficient inactivation of "wet" samples as compared with "dry" samples. For example, in [7], it was shown that direct treatment of agar surfaces covered with a thin layer of water ("wet" samples) with the dc corona discharges produced a higher inactivation effect as compared with the treatment of "dry" bacterial samples on stainless steel coupons: "Wet" samples required $\sim 1.5-2$-fold lower charge dose per $1 \mathrm{log}$ reduction of $E$. coli as compared with "dry" samples. In this paper, bacterial suspensions were spread onto the surface of the agar plates, and once the sample had been absorbed onto the agar surface $(\sim 5 \mathrm{~min})$, the plates were exposed to the corona discharges. This ensured the absence of any water layer on the agar surfaces in the tests reported in this paper. Also, in the case of the indirect treatment in the absence of charged particles, the production of hydrogen peroxide will be reduced, and other mechanisms of interaction between neutral species and microorganisms may be involved. For example, $\mathrm{OH}$ radicals can easily pass through biological membranes, and electrically neutral hydroxyl radicals and other ROS can cause oxidative damage to proteins and DNA.

As discussed in Section IV-B, in order to evaluate the possible effect of plasma-generated active species on agar, the agar plates with no microorganisms were treated with positive and negative indirect corona discharges for $120 \mathrm{~s}$. It was found that neither positive nor negative indirect treatment induced toxicity of the agar plates, indicating that the present indirect treatment does not induce significant changes in the chemical properties of nutrient agar (such as noticeable production of hydrogen peroxide which could affect the development of microorganisms). It has been reported in the literature that ozone in air with concentration of a few hundreds of parts per million can effectively kill microorganisms on agar plates. Kowalski et al. [37] describe tests in which ozone was generated using a corona discharge ozone generator (air was used as a working media). Ozone was delivered into a closed chamber were agar plates seeded with microorganisms (E. coli and $S$. aureus) were located. The minimum ozone concentration used in these tests was $300 \mathrm{ppm}$, and the minimum exposure time was $15 \mathrm{~s}$. The authors of [37] reported that this treatment resulted in $94.4 \%$ inactivation of E. coli and $99.6 \%$ inactivation of $S$. aureus (control sample populations were $1.8 \cdot 10^{5}$ and $1.88 \cdot 10^{5} \mathrm{CFU} /$ plate, respectively). The authors showed that $S$. aureus has a higher sensitivity to ozone at the initial stage of treatment (first $\sim 20 \mathrm{~s}$ ); however, the paper does not discuss any specific processes and mechanisms which are responsible for this difference in ozone sensitivity. It was also found that ozone inactivation efficiencies for treatment times above $\sim 60 \mathrm{~s}$ are very similar for these two microorganisms, and on this basis, the authors concluded that the ozone resistance mechanisms are not species dependent. The authors measured only $\mathrm{O}_{3}$ concentration in their tests; however, as discussed earlier, the corona discharges in air generate other toxic (reactive oxygen and nitrogen) species which can also produce a noticeable bactericidal effect [11], [38]. The results of [37] are in good agreement with that of this paper in which a higher sensitivity of $S$. aureus to indirect corona treatment has been observed. Potentially, this higher sensitivity of the Gram-positive $S$. aureus to plasma treatment as compared with the Gram-negative $E$. coli can be explained by the secondary outer cell membrane of Gram-negative bacteria which provides an elevated level of protection against external stresses. Similar effect has been observed in [39] in which these two species of microorganism were subjected to the action of the ionization products generated by a candle's flame.

In the recent unpublished work conducted by the authors, ozone generated using a DBD system fed with bottled oxygen ( $\sim 7 \%$ relative humidity) has been used in order to confirm the inactivation effect of ozone. The lifetime of singlet oxygen produced by the DBD in a gaseous atmosphere is relatively short, in the order of milliseconds [40]; therefore, it can be assumed that the role of this active oxygen species in the inactivation process is minimal. The concentration of DBDproduced ozone was $\sim 70-80 \mathrm{ppm}$, and the treatment time of the agar plates seeded with E. coli and S. aureus and located in the test cell shown in Fig. 1 was 120 s. More than 99\% inactivation of the microorganisms was achieved in these tests which confirms that plasma-generated ozone can produce a significant bactericidal effect.

The electric field in the test cell has been simulated using an electrostatic solver. It has been shown that the electric field "leakage" through the mesh is minimal and the electrostatic field at the agar surface is absent. Therefore, the electric field does not contribute to the inactivation of microorganisms in the present conditions.

Fig. 11 shows cumulative data on the inactivation efficiency as a function of ozone concentration measured in the tests for both tested microorganisms, E. coli and S. aureus. Data represented in these graphs suggest that $S$. aureus is more sensitive to the indirect corona treatment (ozone produced by these discharges) than E. coli.

The correlation between inactivation efficiency and the level of ozone produced by discharges, as shown in Fig. 11, suggests that, in the case of such indirect treatment when biological samples are located behind the grounded electrode (which prevents the direct action of the charge particles and electric field), ozone may be the main factor which is responsible for this bactericidal action. However, further investigations are planned in order to establish the role of other chemically active species in the bactericidal action of indirect corona discharges. 

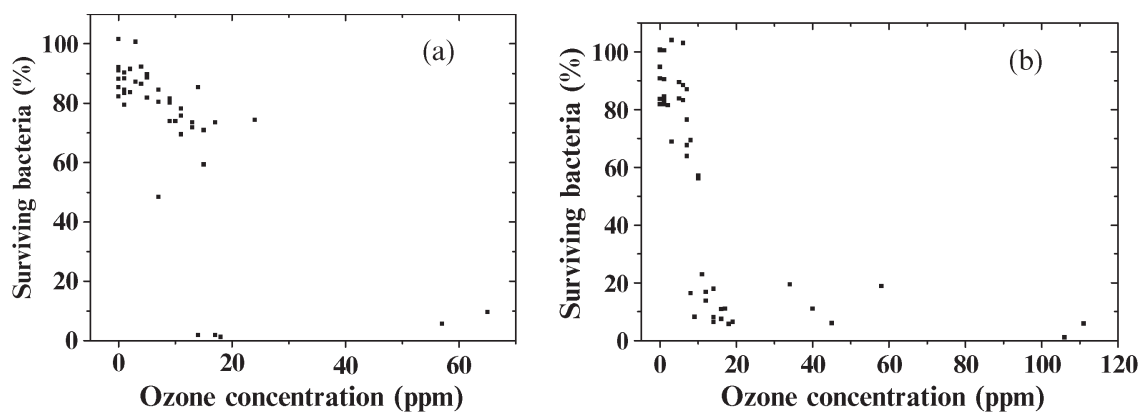

Fig. 11. Bactericidal effect for (a) E. coli and (b) S. aureus as a function of measured ozone concentrations.

\section{Conclusion}

As a result of this study, it has been shown that impulsive corona discharges in air have a strong bactericidal effect. Neutral reactive oxygen and nitrogen species produced by these discharges affect microorganisms and induce chemically generated stresses which can result in the inactivation of microorganisms. Ozone has been selected as an indicator of ROS production in the corona discharges, and it has been shown that there is a correlation between ozone generation and the bactericidal effects induced by indirect corona treatment. The exact mechanism of this effect is still unclear and requires further investigation, including analysis and monitoring of the production of different chemically active species in the corona discharges.

\section{REFERENCES}

[1] J.-S. Chang, P. Lawless, and T. Yamamoto, "Corona discharge processes," IEEE Trans. Plasma Sci., vol. 19, no. 6, pp. 1152-1166, Dec. 1991.

[2] R. Peyrous, "The effect of relative humidity on ozone production by corona discharge in oxygen or air-A numerical simulation-Part II: Air," Ozone, Sci. Eng., vol. 12, no. 1, pp. 41-64, 1990.

[3] I. D. Chalmers, L. Zanella, and S. J. MacGregor, "Ozone synthesis in oxygen in a dielectric barrier free configuration," in 10th IEEE Int. Pulsed Power Conf., Albuquerque, NM, 1995, vol. 2, pp. 1249-1254.

[4] K. Parker, Electrical Operation of Electrostatic Precipitators. London, U.K.: The Institution of Electrical Engineers, 2003.

[5] A. Fridman and L. Kennedy, Plasma Physics and Engineering. New York: Taylor \&Francis, 2004.

[6] E. Moreau, "Airflow control by non-thermal plasma actuators," J. Phys. D, Appl. Phys., vol. 40, no. 3, pp. 605-636, Feb. 2007.

[7] D. Dobrynin, G. Friedman, A. Fridman, and A. Starikovskiy, "Inactivation of bacteria using dc corona discharge: Role of ions and humidity," New J. Phys., vol. 13, pp. 103033-1-103033-13, Oct. 2011.

[8] D. Dobrynin, G. Fridman, G. Friedman, and A. Fridman, "Physical and biological mechanisms of direct plasma interaction with living tissue," New J. Phys., vol. 11, pp. 115020-1-115020-26, Nov. 2009.

[9] G. Morfill, T. Shimizu, B. Steffes, and H.-U. Schmidt, "Nosocomial infections-A new approach towards preventive medicine using plasmas," New J. Phys., vol. 11, pp. 115019-1-115019-10, Nov. 2009.

[10] J. Sousa, K. Niemi, L. Cox, Q. Algwari, T. Gans, and D. O'Connell, "Cold atmospheric pressure plasma jets as sources of singlet delta oxygen for biomedical applications," J. Appl. Phys., vol. 109, no. 12, pp. 123302-1123302-8, Jun. 2011.

[11] M. Laroussi and F. Leipold, "Evaluation of the roles of reactive species, heat, and UV radiation in the inactivation of bacterial cells by air plasmas at atmospheric pressure," Int. J. Mass Spectrom., vol. 233, no. 1-3, pp. 8186, Apr. 2004

[12] M. Kong, G. Kroesen, G. Morfill, T. Nosenko, T. Shimizu, J. van Dijk, and J. Zimmermann, "Plasma medicine: An introductory review," New J. Phys., vol. 11, pp. 115012-1-115012-35, Nov. 2009.

[13] V. Scholtz, J. Julak, V. Kriha, and J. Mosinger, "Decontamination effects of low-temperature plasma generated by corona discharge. Part I: An overview," Prague Med. Rep., vol. 108, no. 2, pp. 115-127, 2007.
[14] M. Korachi, C. Gurol, and N. Aslan, "Atmospheric plasma discharge sterilization effects on whole cell fatty acid profiles of Escherichia coli and Staphylococcus aureus," J. Electrostat., vol. 68, no. 6, pp. 508-512, Dec. 2010.

[15] K. Kerr, C. Beggs, S. Dean, J. Thornton, J. Donnely, N. Todd, P. Sleigh, A. Qureshi, and C. Taylor, "Air ionisation and colonisation/infection with methicillin-resistant Staphylococcus aureus and Acinetobacter species in an intensive care unit," Intensive Care Med., vol. 32, no. 2, pp. 315-317, Feb. 2006.

[16] L. Fletcher, L. Gaunt, C. Beggs, S. Shepherd, P. Sleigh, C. Noakes, and K. Kerr, "Bacterial action of positive and negative ions in air," $B M C$ Microbiol., vol. 7, p. 32, Apr. 2007.

[17] Z. Machala, L. Chladekova, and M. Pelach, "Plasma agents in biodecontamination by de discharges in atmospheric air," J. Phys. D, Appl.Phys., vol. 43, no. 22, pp. 222001-1-2220017, Jun. 2010.

[18] E. van Heesch, G. Winands, and A. Pemen, "Evaluation of pulsed streamer corona experiments to determine the $\mathrm{O} *$ radical yield," J. Phys. D, Appl. Phys., vol. 41, no. 23, pp. 234015-1-234015-5, Dec. 2008.

[19] A. Fridman, A. Chirokov, and A. Gutsol, "Non-thermal atmospheric pressure discharges," J. Phys. D, Appl. Phys., vol. 38, no. 2, pp. R1-R24, Jan. 2005.

[20] Y. Raizer, Gas Discharge Physics. New York: Springer-Verlag, 1991.

[21] F. Grange, N. Soulem, J. Loiseau, and N. Spyrou, "Numerical and experimental determination of ionizing front velocity in a dc point-to-plane corona discharge," J. Phys. D, Appl. Phys., vol. 28, no. 8, pp. 1619-1629, Aug. 1995.

[22] F. Pontiga, C. Soria, A. Castellanos, and J. Skalny, "A study of ozone generation by negative corona discharge through different plasma chemistry models," Ozone, Sci. Eng., vol. 24, no. 6, pp. 447-462, 2002.

[23] S. Joshi, M. Cooper, A. Yost, M. Paff, U. Ercan, G. Fridman, G. Friedman, A. Fridman, and A. Brooks, "Nonthermal dielectric-barrier discharge plasma-induced inactivation involves oxidative DNA damage and membrane lipid peroxidation in Escherichia coli," Antimicrob. Agents Chemother, vol. 55, no. 3, pp. 1053-1062, Mar. 2011.

[24] K. Yanallah, F. Pontiga, A. Fernandez-Rueda, and A. Castellanos, "Experimental investigation and numerical modeling of positive corona discharges: Ozone generation," J. Phys. D, Appl. Phys., vol. 42, no. 6, pp. 065202-1-065202-8, Mar. 2009.

[25] L. Gaunt, C. Beggs, and G. Georghiou, "Bacterial action of the reactive species produced by gas-discharge non-thermal plasma at atmospheric pressure: A review," IEEE Trans. Plasma Sci., vol. 34, no. 4, pp. $1257-$ 1269, Aug. 2006

[26] F. Pontiga, H. Moreno, A. Femaindez-Rueda, and A. Castellanost, "Corona discharge in flowing synthetic air," in Proc. IEEE Conf. Elect. Insul. Dielect. Phenom., 2008, pp. 618-621.

[27] D. Antao, D. Staack, A. Fridman, and B. Farouk, "Atmospheric pressure dc corona discharges: Operating regimes and potential applications," Plasma Sources Sci. Technol., vol. 18, no. 3, pp. 035016-1-035016-11, Aug. 2009.

[28] M. M. Shahin, "Mass-spectrometric studies of corona discharges in air at atmospheric pressures," J. Chem. Phys., vol. 45, no. 7, pp. 2600-2605, Oct. 1966.

[29] J. M. Koutsoubis and S. J. MacGregor, "Electrode erosion and lifetime performance of a high repetition rate, triggered, corona stabilised switch in air," J. Phys. D, Appl. Phys., vol. 33, no. 9, pp. 1093-1103, May 2000.

[30] F. Leipold, "Inactivation of microorganisms by means of low temperature atmospheric discharge plasma," in Proc. 28th Int. Conf. Phys. Ionised Gases, Prague, Czech Republic, 2007, pp. 1403-1405. 
[31] I. V. Timoshkin, S. J. MacGregor, R. A. Fouracre, B. H. Crichton, and J. G. Anderson, "Transient electric field across cellular membranes: Pulsed electric field treatment of microbial cells," J. Phys. D, Appl. Phys., vol. 39, no. 3, pp. 596-603, Feb. 2006.

[32] D. A. Mendis, M. Rosenberg, and F. Azam, "A note on the possible electrostatic disruption of bacteria," IEEE Trans. Plasma Sci., vol. 28, no. 4, pp. 1304-1306, Aug. 2000.

[33] D. Bannerman, M. Paape, J. Lee, X. Zhao, J. Hope, and P. Rainard, "Escherichia coli and Staphylococcus aureus elicit differential innate immune responses following intramammary infection," Clin. Diagn. Lab. Immunol., vol. 11, no. 3, pp. 463-472, May 2004.

[34] G. Winands, Efficient streamer plasma treatment, Proefschrift 2007.

[35] K. Weltman and T. von Woedtke, "Basic requirements for plasma sources in medicine," Eur. Phys. J. Appl. Phys., vol. 55, no. 1, pp. 13870-1-1387010, Jul. 2011.

[36] F. Leipold, Y. Kusano, F. Hansen, and T. Jacobsen, "Decontamination of a rotating cutting tool during operation by means of atmospheric pressure plasmas," Food Control, vol. 21, no. 8, pp. 1194-1198, Aug. 2010.

[37] W. Kowalski, W. Bahnfleth, and T. Whittam, "Bactericidal effect of high airborne ozone concentrations on Escherichia coli and Staphylococcus aureus," Ozone Sci. Eng., vol. 20, pp. 205-221, Apr. 1998.

[38] D. Dobrynin, K. Arjunan, A. Fridman, G. Fridman, and A. Morss Clyne, "Direct and controllable nitric oxide delivery into biologic media and living cells by a pin-to-hall spark discharge (PHD) plasma," J. Phys. D, Appl. Phys., vol. 44, no. 7, pp. 075201-1-075201-10, Feb. 2011.

[39] L. Gaunt, S. Higgins, and J. Huges, "Interaction of air ions and bactericidal vapours to control micro-organisms," J. Appl. Microbiol., vol. 99, pp. 1324-1329, 2005.

[40] G. Khalil, A. Chang, M. Gouterman, J. B. Callis, L. Dalton, N. Turro, and S. Jockusch, "Oxygen pressure measurement using singlet oxygen emission," Rev. Sci. Instrum., vol. 76, no. 5, pp. 054101-1-054101-8, May 2005 .

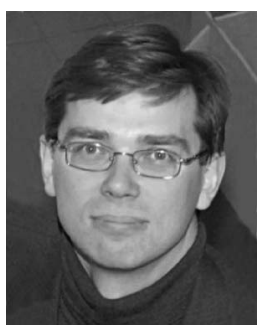

Igor V. Timoshkin (M'07) received the degree in physics from the Moscow State University (MSU), Moscow, Russia, in 1992 and the Diploma and the $\mathrm{Ph} . \mathrm{D}$. degree from the Imperial College of Science, Technology and Medicine (ICSTM), London, U.K., in 2001.

After graduation from MSU, he worked as a Researcher at Moscow State Agro-Engineering University, Moscow, and then at the Institute for High Temperatures of Russian Academy of Sciences before moving to ICSTM in 1997. He joined the Department of Electronic and Electrical Engineering, University of Strathclyde, Glasgow, U.K., in 2001 as an Academic Visitor, where he became a Research Fellow in 2002, a Lecturer in 2006, and a Senior Lecturer in 2011. His research interests include properties of solid and liquid dielectric materials, electronics of plasma discharges in condensed media, practical applications of electrohydraulic and high-power ultrasound pulses, biodielectrics, and effects of electromagnetic fields on biological objects.

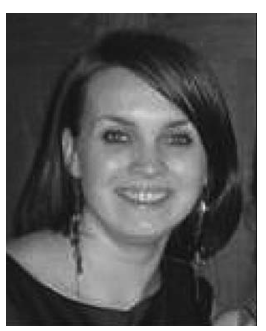

Michelle Maclean was born on the Isle of Lewis, Scotland, in 1980. She received the B.Sc. (first class honors) degree in microbiology and immunology and the Ph.D. degree in electronic and electrical engineering from the University of Strathclyde, Glasgow, U.K., in 2002 and 2006, respectively.

She is currently working as a Research Fellow at the Robertson Trust Laboratory for Electronic Sterilization Technologies at the University of Strathclyde, and her interdisciplinary research work involves the development and application of novel electrotechnologies for biological decontamination and sterilization applications in clinical and public health environments.

Dr. Maclean is a member of the Society for General Microbiology and The American Society of Microbiology.

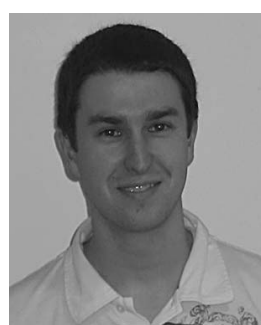

Mark P. Wilson (M'10) was born in Stranraer, Scotland, in 1982. He received the B.Eng. (with honors), M.Phil., and Ph.D. degrees in electronic and electrical engineering from the University of Strathclyde, Glasgow, U.K., in 2004, 2007, and 2011, respectively.

$\mathrm{He}$ is currently working as a Teaching Associate at the University of Strathclyde, where he continues to investigate surface flashover of solids immersed in insulating oil.

Dr. Wilson is a member of the IEEE Nuclear and Plasma Sciences Society, from whom he received a Graduate Scholarship Award in 2011, the IEEE Dielectrics and Electrical Insulation Society, and the IET.

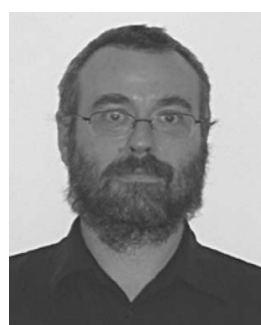

Martin J. Given (M'99-SM'11) received the degree in physics from the University of Sussex, Brighton, U.K., in 1981 and the Ph.D. in electronic and electrical engineering from the University of Strathclyde, Glasgow, U.K., in 1996.

$\mathrm{He}$ is currently a Senior Lecturer with the Department of Electronic and Electrical Engineering, University of Strathclyde. His research interests include aging processes and condition monitoring in solid and liquid insulation systems, high-speed switching, and pulse power applications.

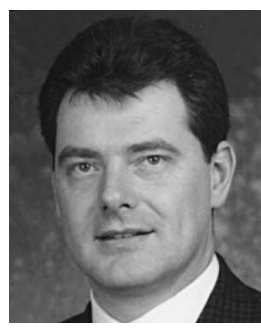

Scott J. MacGregor (M'95) received the B.Sc. and $\mathrm{Ph} . \mathrm{D}$. degrees from the University of Strathclyde, Glasgow, U.K., in 1982 and 1986, respectively.

He became a Pulsed Power Research Fellow in 1986 and a Lecturer in pulsed-power technology in 1989. In 1994, he became a Senior Lecturer, with a promotion to Reader and Professor of High Voltage Engineering in 1999 and 2001, respectively. From January 2010, he became a Dean of the Engineering Faculty of the University of Strathclyde. His research interests include high-voltage pulse generation, highfrequency diagnostics, high-power repetitive switching, high-speed switching, electronic methods for food pasteurization and sterilization, generation of highpower ultrasound (HPU), plasma channel drilling, pulsed-plasma cleaning of pipes, and stimulation of oil wells with HPU.

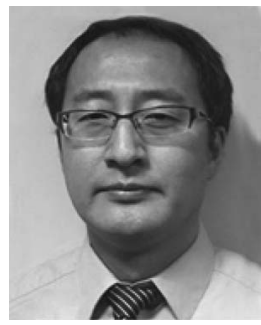

Tao Wang received the B.Eng and M.Sc. degrees from Northeast China Dianli University, Jilin, China, in 1993 and 1996, respectively, and the Ph.D. degree from the University of Strathclyde, Glasgow, U.K., in 2005 .

He then joined the Newland Entech as a Research Fellow developing high-efficiency industrial ozone generator. He joined the Department of Electronic and Electrical Engineering, University of Strathclyde, as a Lecturer in 2010. His research interests include nonthermal gas discharges and their applications in gas synthesis, water disinfection, and advanced oxidation process in water.

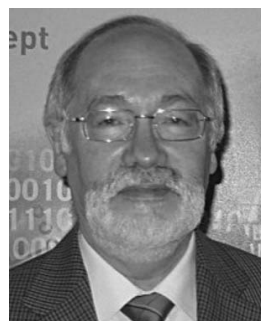

John G. Anderson was born in Glasgow, U.K., on September 2, 1942. He received the B.Sc. degree in applied microbiology and the Ph.D. degree in fungal physiology from the University of Strathclyde, Glasgow, in 1968 and 1971, respectively.

Since 1971, he has been with the Department of Bioscience and Biotechnology, University of Strathclyde, where he became a Professor of Microbiology and the Head of the department. He is currently an Emeritus Professor at the University of Strathclyde. His research interests include various aspects of food, biomedical, and environmental microbiology with interdisciplinary collaboration on the application of electrotechnologies for electronic pasteurization and sterilization. 